\title{
Sorting Ourselves Out: Seeking Consensus on Trafficking in the Beta-Cell
}

\author{
Peter Arvan ${ }^{1}$ and Philippe A. Halban ${ }^{2, *}$ \\ ${ }^{1}$ Division of Metabolism, Endocrinology and Diabetes, \\ University of Michigan Medical Center, Ann Arbor, MI \\ 48109, USA \\ ${ }^{2}$ Research Laboratories, University Medical Center, 1211 \\ Geneva 4, Switzerland \\ * Corresponding author: Philippe Halban, \\ philippe.halban@medecine.unige.ch
}

\begin{abstract}
Biogenesis of the regulated secretory pathway in the pancreatic beta-cell involves packaging of products, notably proinsulin, into immature secretory granules derived from the trans-Golgi network. Proinsulin is converted to insulin and C-peptide as granules mature. Secretory proteins not entering granules are conveyed by transport intermediates directly to the plasma membrane for constitutive secretion. One of the co-authors, Peter Arvan, has proposed that in addition, small vesicles bud from granules to traffic to the endosomal system. From there, some proteins are secreted by a (post-granular) constitutive-like pathway. He argues that retention in granules is facilitated by condensation, rendering soluble products (notably C-peptide and proinsulin) more available for constitutive-like secretion. Thus he argues that prohormone conversion is potentially important in secretory granule biogenesis. The other co-author, Philippe Halban, argues that the post-granular secretory pathway is not of physiological relevance in primary beta-cells, and contests the importance of proinsulin conversion for retention in granules. Both, however, agree that trafficking from granules to endosomes is important, purging granules of unwanted newly synthesized proteins and allowing their traffic to other destinations. In this Traffic Interchange, the two co-authors attempt to reconcile their differences, leading to a common vision of proinsulin trafficking in primary and transformed cells.
\end{abstract}

Key words: C-peptide, insulin, large dense-core vesicles, prohormone conversion, proinsulin, secretory pathways, vesicular trafficking

Received 23 September 2003, revised and accepted for publication 23 October 2003

The classical view of protein secretion was based largely on pioneering studies of Palade $(1,2)$ and later analysis of Kelly (3). Two pathways were proposed. One, the constitutive pathway, was suggested to be ubiquitous and allowed for rapid transfer of proteins in small vesicles from the trans-Golgi network (TGN) to the plasma membrane for spontaneous exocytotic discharge. The second pathway was said to be unique to highly specialized exocrine, endocrine, and neural cells. This so-called regulated secretory pathway involved concentration of a select subpopulation of secretory proteins in the TGN, followed by packaging into nascent secretory granules distinct from small constitutive vesicles, in terms of both their size and function. Delivery to granules was seen as a dynamic selective event involving active sorting and/or targeting. The selected proteins were believed to remain completely stored within granules (also referred to as large dense-core vesicles or LDCVs) until exocytosis that is amplified in response to a stimulus. The detailed description of protein trafficking by Orci in insulin-secreting cells $(4,5)$, and collaboration between Orci and Rothman advanced remarkably our understanding of these pathways at the molecular level (6), in particular describing the nature and function of protein coats enrobing a variety of intracellular transport intermediates (7).

For the purposes of the present discussion, the cardinal feature of the consensus view of the regulated pathway in the 1980s was that the TGN served as the unique sorting station of the pathway. However, it was later proposed that the secretory granule itself serves as a second important sorting station $(8,9)$, and this altered our vocabulary. Sorting in the TGN for dispatch to nascent granules was described as 'sorting for entry'. Sorting within granules was termed 'sorting by retention', involving condensation or perhaps more ordered polymeric assembly of proteins that would be retained in these storage vesicles. Soluble proteins would be available for sequestration in small vesicles budding from young secretory granules. In this way, granule composition could be refined during maturation, introducing the possibility that cargo headed to other destinations could take advantage of young granules as an intermediate station to accomplish their own sorting needs. Some of the soluble proteins exiting young granules would in turn be destined for secretion via a secondary ('postgranular') constitutive-like pathway.

Insulin-secreting cells have provided a useful model for studying the regulated secretory pathway (Figures 1 and 2). Indeed, both the present authors have studied insulin secretion quite extensively. This creates a unique opportunity to compare our views of sorting models for regulated secretory proteins in general and for insulin-containing 


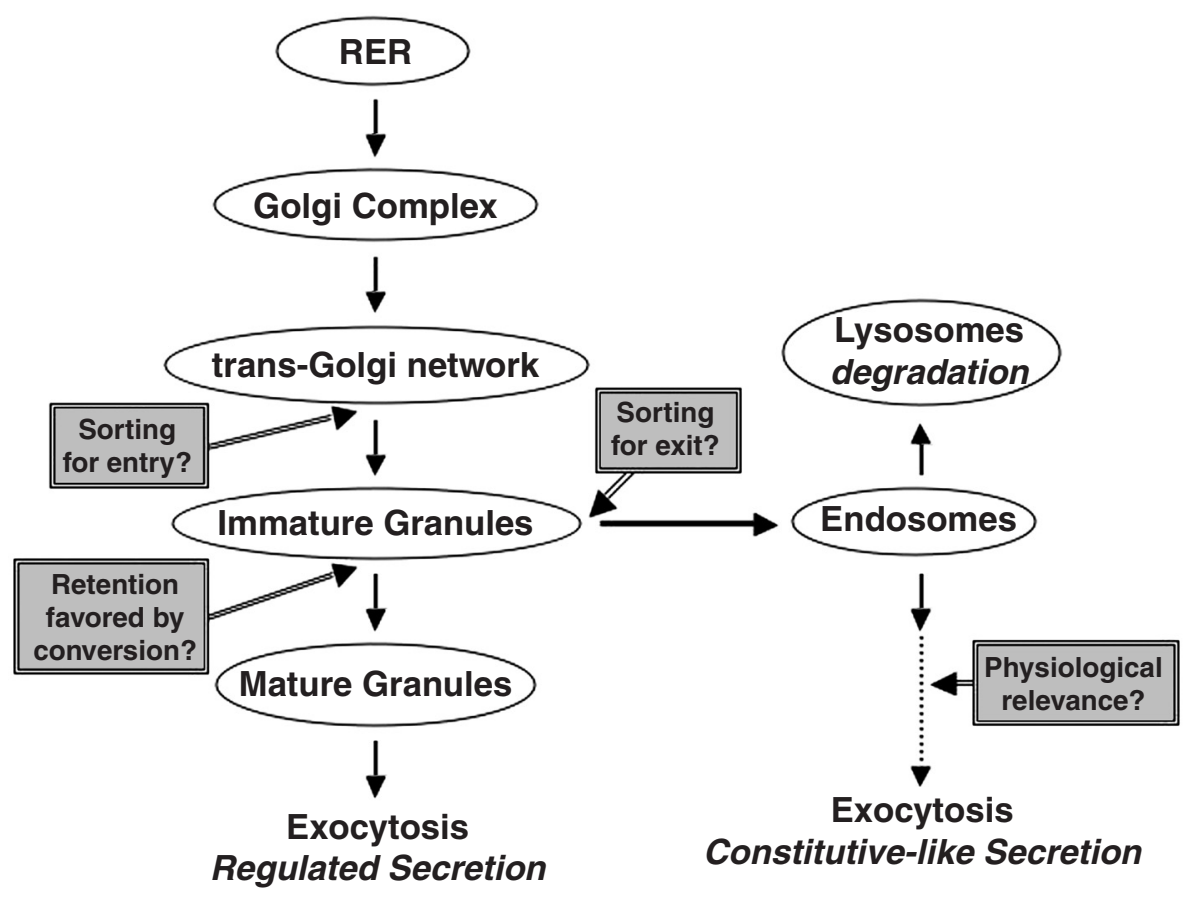

Figure 1: Major steps in trafficking in the pancreatic betacell of proinsulin and its conversion products, insulin and C-peptide. Proinsulin is transported from the RER to the trans-Golgi network where it is packaged into nascent immature secretory granules. As granules mature, vesicles bud from them, carrying cargo to the endosomal compartment and then to lysosomes (degradation) or to the plasma membrane for exocytosis (constitutive-like secretion). Exocytosis of secretory granules arises in response to a stimulus (regulated secretion). The issues/ events debated in this article are indicated by the questions in the gray boxes. granules in particular, highlighting areas where more work is needed. It is our intention here to revisit earlier studies, with emphasis on work from our own laboratories, in an attempt both to debate and to reconcile our different results and conclusions. Each section is prefaced by a background paragraph setting the stage, followed by our individual perspectives, and concluding with an attempt at rapprochement.

\section{'Sorting for Entry': From the TGN to Immature Granules}

\section{Background}

Orci reported that at the level of the Golgi apparatus (pro)insulin immunogold labeling decorates molecules that appear membrane associated, while at the level of mature granules most insulin immunolabeling appears

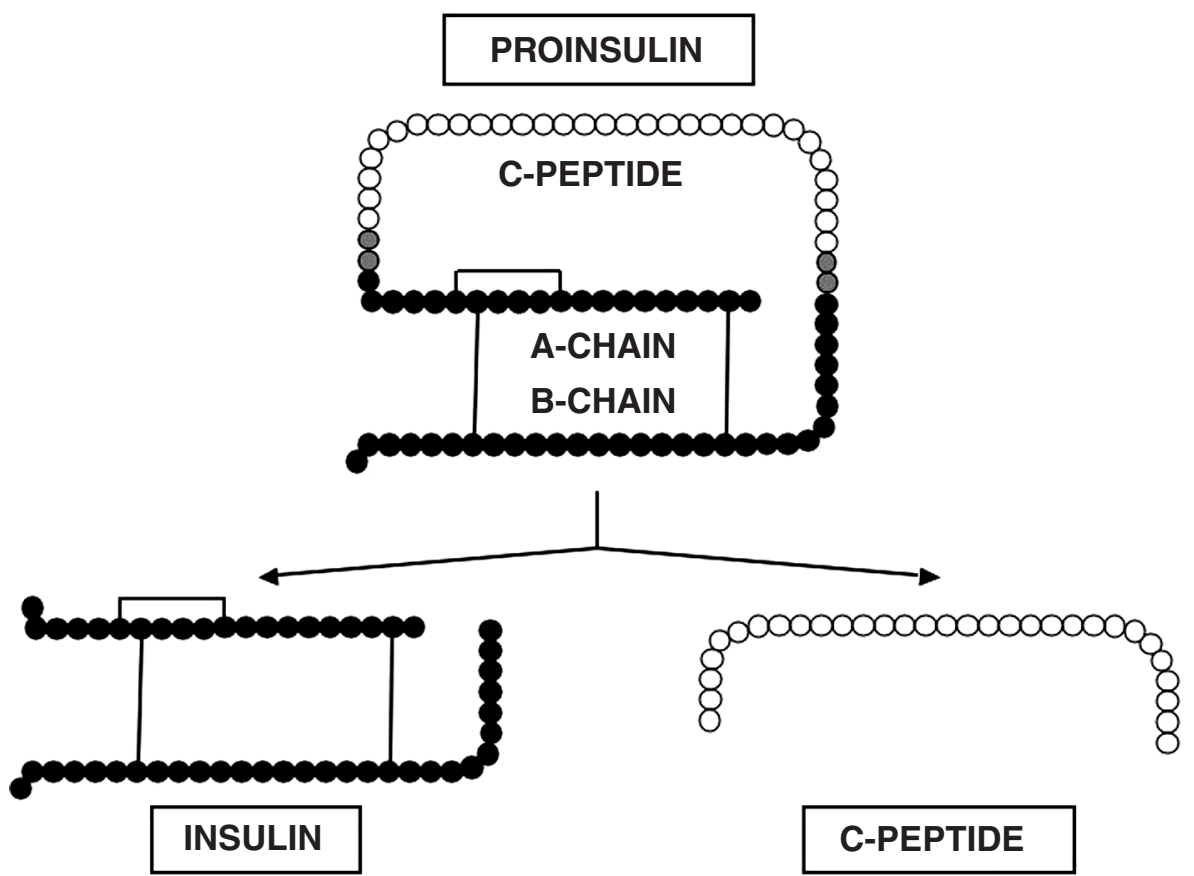

Figure 2: Proinsulin conversion. Proinsulin is converted to insulin and C-peptide by cleavage (by the endoproteases $\mathrm{PC} 1 / 3$ and PC2) at the pairs of basic residues linking $\mathrm{C}$-peptide with the two insulin chains, followed by trimming of C-terminal basic residues (by carboxypeptidase E). 
over the electron-dense granule core (10). He subsequently showed by electron microscopy that the earliest detectable granules are proinsulin-rich/insulin-poor, replete with electron-pale material, carry a (discontinuous) coat of clathrin and have a weakly acidic milieu $(5,11,12)$. It is clear that if regulated secretory protein sorting occurs in the TGN or earlier compartments, proinsulin (and not insulin) must be the subject of such sorting. Several molecular mechanisms have been proposed for such a sorting event. Loh has suggested carboxypeptidase E (CPE) as a sorting 'receptor' for entry of proinsulin and other peptide hormones (and their precursors) into endocrine secretory granules (13). This proposition is both actively contested (14-16) and defended $(17,18)$. Other studies suggest that granin family members might serve in a similar capacity as an organizing principle for endocrine granule biogenesis (19-22). In another proposed mechanism, regulated secretory proteins become associated with distinct membrane microdomains, being either cholesterol-rich $(23,24)$ or rich in glycosphingolipids (25). It remains possible that specific protein receptors bind their targets and in turn provide a link with the appropriate membrane domains (26). Regardless of what mechanism is in play, it must assure selection of both lumenal and membrane proteins, and refinement could continue at the next step of granule maturation.

\section{Talking Point: 'Sorting of proinsulin from the TGN to immature granules is an active process and a prerequisite for regulated insulin secretion'}

The case in favor $(P H)$ : Morphological evidence indicates localization of proinsulin to the limiting membrane of the TGN (10). There is clearly also concentration of clathrin at regions of the TGN membrane engaging in granulogenesis (11). Both speak for sorting of some kind in the TGN with refinement of both cargo (proinsulin and other proteins such as the conversion endoproteases) and granule membrane components (clathrin among others). I cannot imagine how this could ever be a random event. Indeed, we have shown that $>99 \%$ of newly synthesized proinsulin (in primary rat beta-cells) is directed to the regulated secretory pathway (27). Now, one could reason that this is the reflection of sorting within granules. I recognize that our studies focused on the percentage of proinsulin secreted in a constitutive or regulated fashion, and in this sense we did not distinguish between entrapment (sorting) in granules and true sorting in the TGN. We shall come back to this later. It will also be important to take into consideration that even if proinsulin is not converted, it is still secreted efficiently via the regulated pathway. This in itself argues against significant sorting of proinsulin away from granules (see below).

It was proposed over 20 years ago that clathrin might play a role in sorting proinsulin from the TGN, by analogy with its role in the internalization of plasma membrane recep- tors after binding to their ligand (insulin, for example) (4). We do not think this is the case since expression of the Hub peptide (which acts as a dominant-negative mutant of clathrin) in primary rat beta-cells does not affect to any meaningful extent the efficiency of delivery of proinsulin to granules or the retention of proinsulin, insulin or C-peptide within granules (28). As discussed below, the Hub peptide did, however, alter the stability of C-peptide in granules, possibly reflecting impaired clearance of proteases from maturing granules.

Further information comes from studies on the trafficking in beta-cells of secretory proteins not normally destined for regulated secretion. We have thus shown that the secretory form of alkaline phosphatase (SEAP) when expressed in beta-cells is secreted constitutively (29). This was defined as the combination of a high rate of basal secretion and a low index of stimulation. That being said, there was modest stimulation of secretion by secretagogues and we accept that some SEAP may have entered granules. Indeed, the sorting process in the TGN is surely not $100 \%$ efficient. Any leakiness in the system would allow some unwanted proteins to enter granules. I agree that it would be important to be able to purge such proteins from granules as they mature. We were not able to follow the kinetics of SEAP trafficking and cannot therefore pass judgment on whether any molecules in granules are retained there or simply in temporary passage prior to removal by the purging mechanism. In this same study we were, however, surprised to discover that a secretory form of green fluorescent protein (GFP with an N-terminal signal peptide extension) was packaged in granules, retained therein and secreted in response to secretagogues (29). Presumably, GFP (a jellyfish protein not normally destined for secretion), once in this unnatural setting of the TGN of a secretory cell, behaves by chance like a regulated secretory protein, perhaps by virtue of its ability to form intermolecular cross-linked polymers (30). At the least, I admit that this casts aspersions on the specificity of the TGN sorting process!

Counter point (PA): Let us see if we can further open up the interpretations of the cited morphological evidence (10). Even the original study indicated that proinsulin immunogold decorates the lumenal aspect of membranes throughout the Golgi stack, not just in the TGN (which had not yet been so named in 1984). This suggests three possibilities. The trivial one would be, as immunogold technique requires relatively light fixation (i.e. chemical cross-linking), that fixation to membrane components is better than soluble components in the Golgi lumen. Indeed, by electron microscopy, the lumen of Golgi cisternae not infrequently looks like empty space, although this is clearly not just a 'water space'. A second possibility (not exclusive of the first) is that proinsulin, like certain other regulated secretory proteins (25), associates with raft 


\section{Arvan and Halban}

glycosphingolipids which are synthesized in the ER and may be modified in the Golgi complex (31-33). A third possibility is proinsulin association with a proteinaceous sorting receptor. Of course, the identification of CPE as a protein which also associates with lipid rafts could potentially satisfy all of the above requirements. However, the finding that CPE association with lipid rafts occurs only in the TGN and not earlier may be inconsistent with proinsulin's membrane association throughout the entire Golgi complex (and even before). and it would help if it could be shown that the stoichiometry of CPE protein expression is at least one sixth that of proinsulin [assuming proinsulin is quantitatively hexameric in the Golgi complex (34)], while noting that only a subset of CPE molecules are competent for potential sorting. Your paper of 1987 showing that $>99 \%$ of proinsulin enters granules in the beta-cells of pancreatic islets is the gold standard of our field (27). What does this say about TGN-based sorting of proinsulin? Let me give an example of why I feel unclear about this. In endocrine and exocrine cells, it is typical to have $50 \%$ (or more) of all translation devoted to the synthesis of secretory proteins, and the secretory organelles occupy an overwhelming fraction of cytoplasmic volume, i.e. there is a veritable river of protein flow through the secretory pathway to young granules. I certainly would not call proinsulin flow to granules a random event, but neither does this prove the existence of a specific TGN-based sorting mechanism to enter immature granules. This would be perhaps the simplest way to interpret your interesting studies with secretory GFP. The essential point to demonstrate TGN-based sorting would be to identify soluble secretory proteins that do NOT enter granules. At the same time, even if most secretory proteins can travel to a specific destination without specific sorting signal recognition, this does not exclude that some proteins, in some cells, may have precisely such recognition (35).

Towards consensus: Unmistakably, the appearance of clathrin patches, buds, or vesicles is indicative of sorting. In most cases the presence of clathrin means recruitment via suitable membrane protein signals in the cytosolic domains, along with appropriate accessory proteins to stabilize clathrin at the membrane. The presence of such membrane proteins (mannose phosphate receptors, furin, and others) both at the TGN and in immature granules is established fact. Orci's hallmark demonstration of the disappearance of clathrin from maturing secretory granules is highly suggestive that, along the TGN-immature granulemature granule route, material is being selectively removed (36). The work using arginine/lysine analogs (37-39) and the more recent use of the dominant negative clathrin hub fragment (28) seems to leave little doubt that clathrin-mediated vesicle budding cannot be necessary for creation of new insulin granules but is so for refinement, i.e. sorting, during maturation of the Golgi/post-Golgi portion of the secretory pathway. Recent results suggest that even the CPEfat mutant can deliver proinsulin into secretory granules (17) provided that proinsulin exhibits a native struc- ture so as to present discrete residues comprising a putative binding site to CPE (18). These latter studies expressing mutant proinsulins for targeting to secretory granules in AtT20 cells are quite interesting but somewhat perplexing (below). Thus, our current shared view is that proinsulin and other secretory granule proteins may have specific sorting information for entry into secretory granules at the TGN. This information may improve efficiency but is probably not an absolute requirement for entry into granules, and it is likely to be employed by only a fraction of the molecules that actually enter newly forming granules. This would constitute 'refined bulk-flow' with both aspects (massive amounts of protein delivered to the TGN and some element of sorting/refinement) contributing to the highly efficient delivery of proinsulin to nascent granules.

\section{Proinsulin Conversion and Maturation of the Secretory Granule}

\section{Background}

The feature most typical of secretory granules (from a wide variety of cell types) is the presence by electron microscopy of an electron-dense core in the secretory granule lumen. As alluded to above, Palade and colleagues originally attached great significance to this morphological feature, coining the term 'condensing vacuole' to refer to the initial pregranule (TGN) outpouching in which protein condensation was thought to begin. Nevertheless, originally Orci and later others established progressive concentration of secretory proteins along the entire secretory pathway beginning upon exit from the ER $(40,41)$, which could be consistent with cisternal maturation of the Golgi complex (42). It has been well documented in pancreatic beta-cells that proinsulin (not its conversion products insulin and C-peptide) is initially packaged in immature granules $(4,5)$. Subsequently, granule maturation involves three events that occur on a similar (but perhaps not identical) time-scale: acidification of the granule milieu; conversion of proinsulin to insulin and C-peptide (via proinsulin conversion intermediates); and loss of clathrin $(4,12,39,43)$. The additional step of homotypic fusion of immature secretory granules has been proposed for other cell types $(44,45)$ but there is no evidence for this in the beta-cell. In a pulsechase experiment, the wave of newly synthesized proinsulin reaches a peak in immature granules at approximately $30 \mathrm{~min}$ and has cleared (in favor of mature granules) by $90 \mathrm{~min}$ (4). It should be noted that such experiments documenting granule maturation were performed on primary cells (newborn rat islet monolayers or isolated islets from adult rats).

\section{Talking Point: 'Prohormone conversion in relation to retention within the regulated secretory pathway'}

The case in favor (PA): Many endocrine secretory granule proteins (e.g. growth hormone, prolactin, glycoprotein hormones such as TSH, FSH and LH) undergo no 
Regulated Insulin Secretion

endoproteolysis other than cleavage of the $\mathrm{N}$-terminal signal peptide at the level of the ER, and exocrine cells generally express no specialized enzymes for intragranule endoproteolysis. Thus it seems obvious that endoproteolytic processing cannot be an essential conserved feature of protein storage in secretory granules. Nevertheless, there is evidence in exocrine cells that two distinct proteins initially appearing in immature secretory granules with one stoichiometric ratio are finally stored in mature granules in a different stoichiometric ratio (46). The change in ratio could be mediated by sorting for exit from maturing granules or sorting by retention within maturing granules (or a combination of both). Since sorting for exit can clearly occur (47), why invoke a retention mechanism? The answer is because whenever there is membrane traffic from one compartment to another, this traffic has the potential to also capture soluble proteins in proportion to the relative volume-carrying capacity of the traffic - such is the mechanism by which AP-2/clathrin-coated vesicles can also contribute to fluid phase endocytosis even as they selectively capture receptor-bound ligands (48). If the relative volume remaining in granules is vastly greater than the volume exiting, sorting by retention is not really needed, as only a very small fraction of proteins can be lost nonspecifically. If, on the other hand, the relative volume exiting is appreciable, then protein insolubility within the lumen would be a valuable means to improve granule storage efficiency. As regards proinsulin, biophysical studies performed in dilute solution in vitro suggest that proinsulin hexamers have very poor self-association properties to form higher-order complexes. In addition, a point mutant of proinsulin, HisB10Asp, has unusually poor selfassociation properties (defective for hexamerization) and tends to be associated with enhanced constitutive or constitutive-like secretion $(49,50)$. If, as has been proposed in dozens of reviews, higher-order association of regulated secretory proteins is important for efficient storage in secretory granules (although admittedly the proposition is unproven), then either most proinsulin hexamers are not soluble to begin with (in the Golgi/TGN), or the hexamers go on to become insoluble upon endoproteolytic conversion to insulin. While no studies have yet been published to address the first possibility (biophysical properties of proinsulin hexamers in situ), there is conclusive evidence that processed insulin in granules from some species is an insoluble polymer, in some cases even crystalline. Our data have also suggested that such intragranular insulin polymerization and storage is influenced by both prevailing proton and zinc concentrations (47). These data were obtained in isolated intact pancreatic islets. I acknowledge confusion in the field relating to the role of prohormone processing sites $(51,52)$ and prohormone conversion enzymes (13), vs. actual enzymatic processing at these sites to mature hormone as regards the efficiency of intragranule storage. Each of these theories has their proponents, but we have favored actual processing because (a) this triggers an unmistakable biophysical change, and (b) we have evidence from $\mathrm{GH} 4 \mathrm{C} 1$ cells that processed insulin is stored better than the proinsulin precursor (53).

We are concerned about the conclusions drawn regarding granule targeting of proinsulin that are based on use of mutants that may seriously alter the three-dimensional structure of the proinsulin molecule. In our recent studies, we discovered heretofore unappreciated folding defects in the insulin moiety (serious enough to interfere with proper formation of the evolutionarily conserved disulfide pairs) when supposedly innocuous mutations such as HisB10Asp or manipulating the C-peptide linker sequence were introduced $(54,55)$. Of crucial importance to the discussion is the surprising finding that this unsuspected misfolding does NOT prevent transit of the mutants to the TGN and later compartments of the secretory pathway. Indeed, a previous result showing fully normal secretory granule targeting of a mutant proinsulin (56) was in fact obtained, although the entire population of mutant proinsulin molecules had mispaired disulfide bonds (54). Thus, the recently proposed proinsulin sorting receptor (18) would need to be able to recognize not only the sorting signal from the native insulin structure but, surprisingly, from an unphysiological nonnative insulin structure as well. Given these facts, I counsel some element of caution in interpreting the trafficking studies of mutant proinsulins, regardless of cell type.

Counter point (PH): We were surprised by your findings $(53,54)$ and decided to study the retention in granules of unconverted proinsulin directly ourselves. For this purpose, we expressed in rat islet cells [rather than $\mathrm{GH} 4$ or AtT20 (53) cells or yeast (55)] a mutant human proinsulin in which basic residues at both the endoprotease cleavage sites implicated in conversion were changed to neutral residues. This results in a proinsulin molecule that cannot be cleaved at either of the two junctions linking C-peptide to the two insulin (A- and B-) chains. Our results were in clear opposition to yours (57). The mutant proinsulin was sorted efficiently to granules and, more to the point, appeared to be retained in granules (as made evident by its availability for regulated secretion in response to stimulation) as efficiently as fully processed insulin. Significantly, we demonstrated efficient retention in granules for prolonged periods of time ( $7 \mathrm{~h})$, using a time-course for pulsechase comparable to your own, Peter. In point of fact, and even leaving aside possible differences in between celltypes used for study (see below), I remain perplexed by the time-course for removal of proinsulin from granules that you have observed. This seems to take several hours and is as such not at all compatible with the welldocumented time-course for granule maturation mentioned above. Does granule maturation take much longer in transformed cells? If so, it must be uncoupled from proinsulin conversion that is somewhat delayed in some transformed cells but not to such a great extent.

I do not see any evidence in the primary beta-cell that insulin is better retained in granules than proinsulin. 


\section{Arvan and Halban}

Indeed, I am not sure that one could address this experimentally in this cellular setting. We discuss below and seem to agree that trafficking of proinsulin (and C-peptide) out of granules is not of quantitative significance in primary beta-cells. How, then, can one test whether conversion to insulin favors retention in granules? Your studies on proinsulin folding and condensation are extremely elegant and the results compelling - but they do not answer the question I have just raised.

We also disagree on the relevance of insulin crystallization in granules. While this occurs in many animal species, it is not an absolute requirement for well-regulated insulin secretion: guinea-pig insulin does not crystallize (since it cannot co-ordinate $\mathrm{Zn}$ as most other mammalian insulin), yet these animals do not suffer from any detectable metabolic disorder and their granules appear replete with insulin! I am less worried about this than you may be, since I see no reason for active retention of insulin in granules (by crystallization or any other means). It will stay there of its own accord along with proinsulin and C-peptide for the simple but excellent reason that there is so little (bulkflow) traffic out of granules. Why evolution has favored insulin crystallization in so many species is certainly intriguing. It may reflect the need for storing much higher amounts of insulin in granules in comparison to other hormones in non-beta-cells.

Towards consensus: We both agree that non-beta cells are an unphysiological location in which to test insulin storage. However, in the age of surrogate and artificial beta-cells (58), perhaps such a system might ultimately prove to have physiological relevance after all. It is a tough call to know what is more unphysiological - expressing the physiological substrate (proinsulin) in an unphysiological cell line (i.e. GH4C1 or AtT20) or expressing the unphysiological substrate (mutant proinsulin) in physiological cells (islet beta-cells). It would appear as though it is the beta-cell that is special rather than the substrate, proinsulin. The interesting question then becomes: what are the special features that mediate protein storage within the granules of beta cells, and are these features the same as those mediating protein storage in the granules of other cell types that maintain a regulated secretory pathway?

\section{The Postgranular Constitutive-Like Secretory Pathway}

\section{Background}

Arvan's lab first coined the term 'constitutive-like' secretion to describe unstimulated secretion of proteins that had already traversed, but were no longer contained within, the secretory granule compartment (59). Recent experiments indicate that such a secretory pathway proceeds via an endosomal intermediate (60). What is the evidence that such a pathway contributes meaningfully to the secretory output of pancreatic beta-cells?

\section{Talking point: The postgranular constitutive-like secretory pathway has no physiological significance in primary beta-cells}

The case in favor $(P H)$ : The two of us appear to disagree fundamentally on this issue. We have certainly followed your studies with great interest and read your papers in detail. Our own studies have been based on the assumption (as first suggested by you) that (soluble) C-peptide would be available for constitutive secretion emanating from granules, whereas (crystalline) insulin would not. Now, it must be admitted that we have not used the same cells as you in all instances. We have favored primary islets or the relatively well-differentiated INS-1 line derived from a rat insulinoma. That being said, you too have had the occasion to use both and, indeed, one of your earliest studies demonstrating constitutive-like secretion of C-peptide was done on rat islets (59). We first noted that even in INS-1 cells only $1.4 \%$ of newly synthesized Cpeptide could possibly have been secreted by this route during a 4-h chase and that in primary rat islets the ratio of insulin: C-peptide remained close to unity, even during a 24-h chase (61), arguing against any significant and disproportionate loss of C-peptide from granules before exocytosis. More recent attempts in our laboratory to measure postgranular constitutive secretion of C-peptide (28) or mutant (unconverted) proinsulin (that should, like C-peptide, be soluble in the granule since it cannot crystallize) (57) from primary rat islets have failed just as conclusively, and we maintain that this pathway can account for secretion of no more than $1 \%$ of soluble granule constituents. With the greatest of respect to you, my good friend, we therefore maintain our position: this pathway is of little if any relevance to the physiology of secretion from beta-cells.

Notwithstanding, we do believe that budding of vesicles from granules is important for purging undesirable components that may have entered them due to the possible 'leakiness' in the sorting process within the TGN alluded to earlier. Indeed, we see this as a critical part of the regulated pathway ensuring, in particular, the removal of proteases that may otherwise degrade physiologically important proteins during their storage within granules and prior to their secretion. We have suggested (based on our studies using the Hub dominant-negative clathrin protein) that clathrin is implicated in this clean-up operation (57). The most recent study from your own laboratory has shed further light on this pathway, showing clearly that there is traffic from granules to endosomes (60). This would be quite in keeping with our postulated role for clathrin given that endosomes are the accepted and preferred destination for clathrin-coated vesicles. As we see it, newly synthesized proteins can and do exit granules as they mature, but this occurs largely by a 'sorting for exit' 
Regulated Insulin Secretion

mechanism for which neither C-peptide nor proinsulin are substrates.

Counter point (PA): Thank you for bringing this to the fore! I don't want to spoil the argument but I think we disagree here very little. We did not maintain previously, nor do we now argue, that the constitutive-like secretion of C-peptide or insulin in normal beta-cells is significant because of its QUANTITY, which is so drastically overshadowed by genuine granule exocytosis. Our argument from the outset has been that constitutive-like secretion of C-peptide or insulin is the price of doing business (i.e. sorting, trafficking) during granule maturation. Having said this, there are a few caveats. First, the finding that certain secretory proteins (not C-peptide or insulin) might use this pathway selectively $(60,62)$ and the fact that this selective secretory trafficking is conserved down to yeast (63) raises new issues about the possible physiological significance for some secretory products. Second, if $>99 \%$ of proinsulin is stored in granules and the remaining tiny fraction is secreted via the constitutive-like pathway, this still leaves essentially no room for direct proinsulin transit from the TGN to the beta-cell surface, a point which is of considerable cell biological significance. Finally, the possibility should not be excluded that operation of the constitutivelike pathway may be regulated $(64,65)$ and potentially amplified in currently unforeseen ways, including in pathological states.

Towards consensus: I think maybe we already have consensus on this one! Our respective studies over the years have led to revision of our original (possibly extreme) positions. This has come about from use in both our laboratories of both primary and transformed cells and careful attention to trafficking of both proinsulin-related and unrelated granule cargo. So where does this leave us? Proteins can enter granules in transit to other destinations. They move out of this compartment in small vesicles on their way to endosomes. Thereafter, some may be released in the constitutive-like pathway while others are degraded. In the beta-cell, this pathway exists and may be important for purging granules of unwanted proteases. However, neither proinsulin nor C-peptide features as a major passenger of this pathway in primary beta-cells. This suggests one of two possibilities: (a) the volume removed in this postgranular pathway relative to that of the granule itself is very small. Random capture (and expulsion from granules) of soluble proteins such as C-peptide is thus also limited in amount; (b) C-peptide, although excluded from the insulin crystal and known to be soluble in the acidic intragranular milieu, may in some way be captured in an intragranular molecular web and thereby not available for the postgranular trafficking pathway. We also agree that granules in transformed cells appear to be less well purged of proteins that are transitory in this compartment in primary cells.

\section{Summary and Perspectives}

We see two major take-home messages from the present debate. The first is that we still know very little about certain key aspects of the regulated secretory pathway in general and of proinsulin trafficking and secretion in particular. The second is that it is quite easy to reach consensus on issues about which we are so ignorant! Joking aside, while we agree that sorting within the TGN may provide an extra degree of refinement above and beyond that afforded by bulk-flow, the underlying mechanism remains elusive and most probably is not applicable to all secretory proteins entering granules. We do believe that in pancreatic beta-cells, proinsulin molecules may indeed use sorting mechanisms to facilitate their entry into granules; however, we presently cannot estimate the fraction of proinsulin molecules that enters granules via selective capture, nor have we yet identified a ready means to distinguish this population from the fraction of proinsulin molecules entering granules in the fluid phase. While prohormone (and proinsulin) conversion may be important for retention in granules in certain situations, neither this nor the trafficking of soluble cargo proteins out of granules is of quantitative importance in the handling of proinsulin and C-peptide in the normal physiology of primary pancreatic beta cells. That being said, this pathway is thought to be operational for purging unwanted lumenal proteins - which may include a subset of secretory proteins as well as proteases normally destined for lysosomes - to the endosomal system in beta-cells and other regulated secretory cell types. Presumably, this utilizes a clathrin-dependent sorting and trafficking pathway.

With the advent of modern techniques for following protein trafficking in living cells in real time, it should be possible to refine our understanding of several of these trafficking events. In particular, with appropriately selected markers, it should begin to be possible to follow the precise timing of events involved in the formation of immature granules and their subsequent maturation. The hunt for genes that regulate the granule biogenesis phenotype is only just beginning, and the increasing availability of dominant-negative or constitutively active proteins implicated in sorting and trafficking should help to clarify further molecular mechanisms underlying these events. The roles of the regulated secretory proteins themselves in driving formation of the secretory granule core structure need to be distinguished (and yet integrated) in a granule biogenesis model that resolves issues regarding the extent to which the immature granule membranes are built from newly synthesized components vs. recycled from previously discharged granules and endosomal storage compartments. All of these future directions are important to understand the differentiated function of regulated secretory cells, and significant progress in these 


\section{Arvan and Halban}

directions will be needed for cell biologists and biotechnologists to develop surrogate beta-cells to supply the world's needs in the future treatment of diabetes.

\section{Acknowledgments}

Work from our laboratories has been supported by the National Institutes of Health DK48280 and an American Diabetes Association Mentor-based fellowship grant to PA and the Swiss National Science Fund (Grant 320080-101902/1) to $\mathrm{PH}$.

\section{References}

1. Palade G. Intracellular aspects of the process of protein synthesis. Science 1975;189:347-358.

2. Farquhar MG, Palade GE. The Golgi apparatus (complex) - (1954-81) - from artifact to center stage. J Cell Biol 1981;91:77s-103s.

3. Kelly RB. Pathways of protein secretion in eukaryotes. Science 1985;230:25-32.

4. Orci L. Macro and micro-domains in the endocrine pancreas. Diabetes 1982;31:538-565.

5. Orci $\mathrm{L}$. The insulin factory. a tour of the plant surroundings and a visit to the assembly line. Diabetologia 1985;28:528-546.

6. Rothman J, Orci L. Molecular dissection of the secretory pathway. Nature 1992;355:409-415.

7. Rothman JE, Orci L. Budding vesicles in living cells. Sci Am 1996; 274:50-55.

8. Arvan $\mathrm{P}$, Castle D. Protein sorting and secretion granule formation in regulated secretory cells. Trends Cell Biol 1992;2:327-331.

9. Arvan P, Castle D. Sorting and storage during secretory granule biogenesis: looking backward and looking forward. Biochem J 1998;332: 593-610.

10. Orci L, Ravazzola M, Perrelet A. Proinsulin associates with Golgi membranes of pancreatic B cells. Proc Natl Acad Sci USA 1984;81:6743-6746.

11. Orci L, Halban P, Amherdt M, Ravazzola M, Vassalli J-D, Perrelet $A$. A clathrin-coated, Golgi-related compartment of the insulin secreting cell accumulates proinsulin in the presence of monensin. Cell 1984;39:39-47.

12. Orci L, Ravazzola M, Amherdt M, Madsen O, Perrelet A, Vassalli JD, Anderson RGW. Conversion of proinsulin to insulin occurs coordinately with acidification of maturing secretory vesicles. J Cell Biol 1986;103:2273-2281.

13. Cool DR, Normant E, Shen F, Chen HC, Pannell L, Zhang Y, Loh YP. Carboxypeptidase $E$ is a regulated secretory pathway sorting receptor: genetic obliteration leads to endocrine disorders in Cpe (fat) mice. Cell 1997:88:73-83.

14. Thiele C, Gerdes HH, Huttner WB. Protein secretion: puzzling receptors. Curr Biol 1997;7:R496-R500.

15. Irminger JC, Verchere CB, Meyer K, Halban PA. Proinsulin targeting to the regulated pathway is not impaired in carboxypeptidase E-deficient Cpefat/Cpefat mice. J Biol Chem 1997;272:27532-27534.

16. Varlamov O, Fricker LD, Furukawa H, Steiner DF, Langley SH, Leiter EH. Beta-cell lines derived from transgenic $\mathrm{Cpe}$ (fat)/Cpe (fat) mice are defective in carboxypeptidase $\mathrm{E}$ and proinsulin processing. Endocrinology 1997;138:4883-4892.

17. Cawley NX, Rodriguez YM, Maldonado A, Loh YP. Trafficking of mutant carboxypeptidase $\mathrm{E}$ to secretory granules in a \{beta\}-cell line derived from Cpefat/Cpefat Mice. Endocrinology 2003;144:292-298.
18. Dhanvantari S, Shen FS, Adams T, Snell CR, Zhang C, Mackin RB, Morris SJ, Loh YP. Disruption of a receptor-mediated mechanism for intracellular sorting of proinsulin in familial hyperproinsulinemia. Mol Endocrinol 2003;17:1856-1867.

19. Yoo SH. $\mathrm{pH}-$ and $\mathrm{Ca}(2+)$-dependent aggregation property of secretory vesicle matrix proteins and the potential role of chromogranins A and B in secretory vesicle biogenesis. J Biol Chem 1996;271: 1558-1565.

20. Natori S, Huttner WB. Chromogranin B (secretogranin I) promotes sorting to the regulated secretory pathway of processing intermediates derived from a peptide hormone precursor. Proc Natl Acad Sci USA 1996;93:4431-4436.

21. Kim T, Tao-Cheng J, Eiden LE, Loh YP. Chromogranin A, an 'on/off' switch controlling dense-core secretory granule biogenesis. Cell 2001;106:499-509.

22. Hosaka M, Watanabe T, Sakai Y, Uchiyama Y, Takeuchi T. Identification of a chromogranin A domain that mediates binding to secretogranin III and targeting to secretory granules in pituitary cells and pancreatic beta-cells. Mol Biol Cell 2002;13:3388-3399.

23. Dhanvantari S, Loh YP. Lipid raft association of carboxypeptidase $E$ is necessary for its function as a regulated secretory pathway sorting receptor. J Biol Chem 2000;275:29887-29893.

24. Wang $Y$, Thiele C, Huttner WB. Cholesterol is required for the formation of regulated and constitutive secretory vesicles from the transGolgi network. Traffic 2000;1:952-962.

25. Blazquez M, Thiele C, Huttner WB, Docherty K, Shennan KIJ. Involvement of the membrane lipid bilayer in sorting prohormone convertase 2 into the regulated secretory pathway. Biochem J 2000;349:843-852.

26. Tooze SA, Martens GJ, Huttner WB. Secretory granule biogenesis: rafting to the SNARE. Trends Cell Biol 2001;11:116-122.

27. Rhodes CJ, Halban PA. Newly synthesized proinsulin/insulin and stored insulin are released from pancreatic $B$ cells predominantly via a regulated, rather than constitutive, pathway. J Cell Biol 1987;105:145-153.

28. Molinete M, Dupuis S, Brodsky FM, Halban PA. Role of clathrin in the regulated secretory pathway of pancreatic beta-cells. J Cell Sci 2001;114:3059-3066.

29. Molinete M, Lilla V, Jain R, Joyce PBM, Gorr SU, Ravazzola M, Halban PA. Trafficking of non-regulated secretory proteins in insulin secreting (INS-1) cells. Diabetologia 2000;43:1157-1164.

30. Jain RK, Joyce PB, Molinete M, Halban PA, Gorr SU. Oligomerization of green fluorescent protein in the secretory pathway of endocrine cells. Biochem J 2001;360:645-649.

31. Buschard K, Josefsen K, Hansen SV, Horn T, Marshall MO, Persson H, Mansson JE, Fredman P. Sulphatide in islets of Langerhans and in organs affected in diabetic late complications: a study in human and animal tissue. Diabetologia 1994;37:1000-1006.

32. Fredman $\mathrm{P}$, Mansson JE, Rynmark BM, Josefsen $K$, Ekblond $A$, Halldner L, Osterbye T, Horn T, Buschard K. The glycosphingolipid sulfatide in the islets of Langerhans in rat pancreas is processed through recycling: possible involvement in insulin trafficking. Glycobiology 2000;10:39-50.

33. Osterbye $T$, Jorgensen $\mathrm{KH}$, Fredman $\mathrm{P}$, Tranum-Jensen J, Kaas A, Brange J, Whittingham JL, Buschard K. Sulfatide promotes the folding of proinsulin, preserves insulin crystals, and mediates its monomerization. Glycobiology 2001;11:473-479.

34. Huang XF, Arvan P. Intracellular transport of proinsulin in pancreatic beta-cells. Structural maturation probed by disulfide accessibility. J Biol Chem 1995;270:20417-20423.

35. Glombik MM, Gerdes HH. Signal-mediated sorting of neuropeptides and prohormones: secretory granule biogenesis revisited. Biochimie 2000;82:315-326.

36. Orci L, Ravazzola M, Storch MJ, Anderson RGW, Vassalli JD, Perrelet A. Proteolytic maturation of insulin is a post-Golgi event which occurs in acidifying clathrin-coated secretory vesicles. Cell 1987;49:865-868. 
Regulated Insulin Secretion

37. Halban PA. Inhibition of proinsulin to insulin conversion in rat islets using arginine and lysine analogs. J Biol Chem 1982;257: 13177-13180.

38. Kuliawat R, Arvan P. Protein targeting via the 'constitutive-like' secretory pathway in isolated pancreatic islets: passive sorting in the immature granule compartment. J Cell Biol 1992;118:521-529.

39. Orci L, Halban P, Amherdt M, Ravazzola M, Vassalli JD, Perrelet A. Nonconverted, amino acid analog-modified proinsulin stays in a Golgi-derived clathrin-coated membrane compartment. J Cell Biol 1984;99: 2187-2192.

40. Bendayan M, Roth J, Perrelet A, Orci L. Quantitative immunocytochemical localization of pancreatic secretory proteins in subcellular compartments of the rat acinar cell. J Histochem Cytochem 1980;28: 149-160.

41. Oprins A, Rabouille C, Posthuma G, Klumperman J, Geuze HJ, Slot JW. The ER to Golgi interface is the major concentration site of secretory proteins in the exocrine pancreatic cell. Traffic 2001;2: 831-838.

42. Arvan $P$, Zhang B, Feng L, Liu M, Kuliawat R. Lumenal protein multimerization in the distal secretory pathway/secretory granules. Curr Opin Cell Biol 2002;14:448-453.

43. Orci L, Ravazzola M, Amherdt M, Madsen O, Vassalli JD, Perrelet A. Direct identification of prohormone conversion site in insulin-secreting cells. Cell 1985;42:671-681.

44. Urbe S, Page LJ, Tooze SA. Homotypic fusion of immature secretory granules during maturation in a cell-free assay. $J$ Cell Biol 1998;143:1831-1844.

45. Wendler F, Page L, Urbe S, Tooze SA. Homotypic fusion of immature secretory granules during maturation requires syntaxin 6. Mol Biol Cell 2001;12:1699-1709.

46. von Zastrow M, Castle JD. Protein sorting among two distinct export pathways occurs from the content of maturing exocrine storage granules. J Cell Biol 1987;105:2675-2684.

47. Kuliawat R, Arvan P. Distinct molecular mechanisms for protein sorting within immature secretory granules of pancreatic beta-cells. J Cell Biol 1994;126:77-86.

48. Damke H, Baba T, van der Bliek AM, Schmid SL. Clathrin-independent pinocytosis is induced in cells overexpressing a temperature-sensitive mutant of dynamin. J Cell Biol 1995;131:69-80.

49. Carroll RJ, Hammer RE, Chan SJ, Swift HH, Rubenstein AH, Steiner DF. A mutant human proinsulin is secreted from islets of Langerhans in increased amounts via an unregulated pathway. Proc Natl Acad Sci USA 1988;85:8943-8947.

50. Gross DJ, Halban PA, Kahn CR, Weir GC, Villa-Komaroff L. Partial diversion of a mutant proinsulin (B10 aspartic acid) from the regulated to the constitutive secretory pathway in transfected AtT-20 cells. Proc Natl Acad Sci USA 1989;86:4107-4111.

51. Paganetti $P$, Scheller $\mathrm{RH}$. Proteolytic processing of the aplysia A peptide precursor in AtT-20 cells. Brain Res 1994;633:53-62.
52. Brechler V, Chu WN, Baxter JD, Thibault G, Reudelhuber TL. A protease processing site is essential for prorenin sorting to the regulated secretory pathway. J Biol Chem 1996;271:20636-20640.

53. Kuliawat R, Prabakaran D, Arvan P. Proinsulin endoproteolysis confers enhanced targeting of processed insulin to the regulated secretory pathway. Mol Biol Cell 2000;11:1959-1972.

54. Liu M, Ramos-Castaneda J, Arvan P. Role of the connecting peptide in insulin biosynthesis. J Biol Chem 2003;278:14798-14805.

55. Zhang $B$, Chang A, Kjeldsen TB, Arvan P. Intracellular retention of newly synthesized insulin in yeast is caused by endoproteolytic processing in the Golgi complex. J Cell Biol 2001;153: 1187-1198.

56. Powell SK, Orci L, Craik CS, Moore HPH. Efficient targeting to storage granules of human proinsulins with altered propeptide domain. J Cell Biol 1988;106:1843-1851.

57. Halban PA, Irminger JC. Mutant proinsulin that cannot be converted is secreted efficiently from primary rat beta-cells via the regulated pathway. Mol Biol Cell 2003;14:1195-1203.

58. Newgard CB, Clark S, Beltrandel, Rio H, Hohmeier HE, Quaade C, Normington $\mathrm{K}$. Engineered cell lines for insulin replacement in diabetes. current status and future prospects. Diabetologia 1997;40 (Suppl. 2): S42-S47.

59. Arvan P, Kuliawat R, Prabakharan D, Zavacki A-M, Elahi D, Wang S, Pilkey D. Protein discharge from immature secretory granules displays both regulated and constitutive characteristics. J Biol Chem 1991;266:14171-14174.

60. Feng L, Arvan P. The trafficking of alpha1-antitrypsin, a post-Golgi secretory pathway marker, in INS-1 pancreatic beta cells. J Biol Chem 2003:278:31486-31494.

61. Neerman-Arbez M \& Halban PA. Novel, non-crinophagic, degradation of connecting peptide in transformed pancreatic beta cells. J Biol Chem 1993;268:16248-16252.

62. Millar CA, Meerloo T, Martin S, Hickson GR, Shimwell NJ, Wakelam MJ, James DE, Gould GW. Adipsin and the glucose transporter GLUT4 traffic to the cell surface via independent pathways in adipocytes. Traffic 2000;1:141-151.

63. Harsay E, Schekman R. A subset of yeast vacuolar protein sorting mutants is blocked in one branch of the exocytic pathway. J Cell Biol 2002;156:271-285.

64. Huang AY, Castle AM, Hinton BT, Castle JD. Resting (basal) secretion of proteins is provided by the minor regulated and constitutive-like pathways and not granule exocytosis in parotid acinar cells. J Biol Chem 2001;276:22296-22306.

65. Castle AM, Huang AY, Castle JD. The minor regulated pathway, a rapid component of salivary secretion, may provide docking/fusion sites for granule exocytosis at the apical surface of acinar cells. J Cell Sci 2002;115:2963-2973. 